\title{
Effect of Different Concentrations of Titanium Dioxide Nanoparticles on the Potential Barrier of Organic Device
}

Sudipta Sen

N. B. Manik

Condensed Matter Physics Research Centre, Department of Physics, Jadavpur University, India

\begin{abstract}
Present work has studied potential barrier of Phenosafranin dye based organic device and has observed influence of different concentrations of titanium dioxide nanoparticles on this parameter. We have made different devices by taking different weight ratios of the dye - nanoparticles blend which are 1:1, 1:2, 1:3 and 1:4. These organic devices have been formed by varying the concentrations of titanium dioxide nanoparticles keeping same dye content. One device is also formed without any nanoparticle to compare influence of nanoparticle on potential barrier of the device. These devices are formed by sandwiching the dye - nanoparticle blend in between the Indium Tin Oxide coated glass and Aluminium coated mylar sheet. The potential barrier is measured from device's $\mathrm{I}-\mathrm{V}$ plot and also by Norde function. These two methods remain in good agreement showing that potential barrier is mostly decreased when the concentration of the titanium dioxide nanoparticles is highest in the blend of Phenosafranin dye and titanium dioxide nanoparticles. The ratio of dye nanoparticle blend of 1:4 shows lowest potential barrier and it is highest when Phenosafranin dye based organic device is made without any nanoparticle. The reduced potential barrier in the presence of higher concentration of nanoparticles can be ascribed to improved filling of traps. Lowered potential barrier at metal - organic contact will improve the charge flow resulting in better performance of the device.
\end{abstract}

Keywords: Metal - Organic Dye Interface; Norde Function; Potential Barrier; Phenosafranin Dye; Titanium dioxide Nanoparticles

\section{Introduction}

Certain features of organic devices such as cost effectiveness, high flexibility, easy processing, light weight and large area fabrication make them highly promising for many devices in recent years [1-3]. The performance of organic electronic devices is strongly 
dependent on the charge flow at metal - organic (M/O) contact when dye is sandwiched in between two metal electrodes having different work functions. The main limitation of this device is the poor charge flow at $\mathrm{M} / \mathrm{O}$ contact. There are many reasons behind the poor charge flow at the contact but in our work, we have ascribed high potential barrier at contact to be the main reason behind the low charge injection process. Earlier in our works, [4-7], we have tried to improve the flow of charge in terms of barrier lowering, trap concentration decreasing by modifying back electrode and also by incorporating different nanoparticles in different organic devices. In present work, variation of nanoparticles concentration has been done to observe its influence on potential barrier at the contact. We have taken Phenosafranin (PSF) dye as the organic material and this dye has been sandwiched in between Indium Tin Oxide (ITO) coated glass and Aluminium coated mylar (Al-M) sheet in absence of any nanoparticle. To observe influence of varying concentration of nanoparticles, we have chosen titanium dioxide $\left(\mathrm{TiO}_{2}\right)$ nanoparticle and have varied its concentration keeping the PSF dye concentration same. Titanium dioxide occurs in three crystalline polymorphs such as rutile, anatase,

and brookite and it has been extensively studied for its interesting electric, magnetic, catalytic, and electrochemical properties [8-9]. In one of our earlier works [10], we have shown the effect of titanium dioxide $\left(\mathrm{TiO}_{2}\right)$ nanoparticle on potential barrier and charge trapping of PSF dye based organic device without varying the concentration of nanoparticles but in this work, variation of concentration of titanium dioxide $\left(\mathrm{TiO}_{2}\right)$ nanoparticle on potential barrier of PSF organic dye based device will be studied in detail. In this work, titanium dioxide has been used in its anatase form. In some previous works, titanium dioxide has been introduced to improve the morphology of active layers in sandwiched structure organic device to increase the efficiency of the device and due to its chemical stability and biocompatibility, $\mathrm{TiO}_{2}$ also finds its application in gas sensors, photocatalytic degradations of organic compounds and photovoltaic and photo electrochemical cells [11-13]. $\mathrm{TiO}_{2}$ has a wide energy gap, a lower recombination rate of electron-hole pairs and high mobility along with controllable size which can be modified by addition of an organic molecule which in turn could change the interactions with other device components [14-15]. $\mathrm{TiO}_{2}$ incorporation will also reduce the sensitivity of the organic semiconductor based device to oxygen and water vapour [16].

The current flow at the metal -organic contact can be either space charge limited current (SCLC) or injection limited current (ILC). From the theoretical calculations, it has been seen that for a potential barrier less than $0.3 \mathrm{eV}$, the current is space charge limited at room temperature [17] and when the interfacial barrier is greater than $0.3 \mathrm{eV}$, current is injection limited. In our work, as potential barrier at the contact has been found to be greater than $0.3 \mathrm{eV}$, we have considered the flow of the current as injection - limited.

We have estimated potential barrier at the metal - organic contact by using Richardson - Schottky (RS) model [18]. We have estimated potential barrier from I -V plot of this device without any nanoparticle and also for different concentrations of $\mathrm{TiO}_{2}$ 
nanoparticles. We have also used Norde method to check the consistency of the obtained data from device's I-V plot.

\section{Materials}

Phenosafranin dye is a cationic dye whose structure is shown in Fig. 1 (a). This dye has been procured from Sigma Aldrich, Germany. Phenazinium dyes have extensive applications in semiconductors [19]. To observe the effect of nanoparticles in this organic dye based device, we have incorporated titanium dioxide nanoparticles $\left(\mathrm{TiO}_{2}\right)$ to the PSF cell. We have used $\mathrm{TiO}_{2}$, which is in anatase form [20]. Its molecular weight is $79.90 \mathrm{~g} / \mathrm{mol}$. We have used $100 \mathrm{~nm}$ size $\mathrm{TiO}_{2}$ nanoparticles. The $\mathrm{TiO}_{2}$ nanoparticles have been brought from Sigma-Aldrich, Germany. Here the structure of the $\mathrm{TiO}_{2}$ nanoparticles is depicted in Fig. 1 (b).

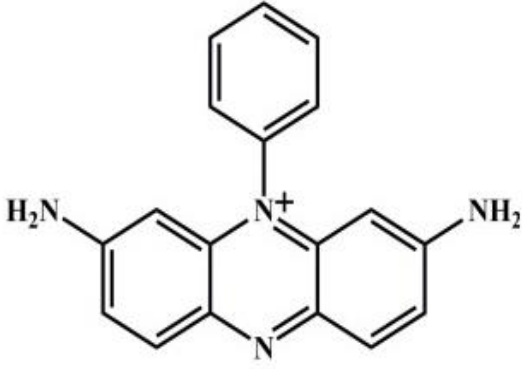

(a)

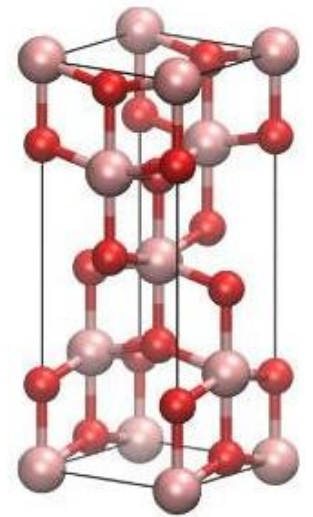

(b)

Fig 1 Structure of (a) Phenosafranin (PSF) dye and (b) Titanium dioxide $\left(\mathrm{TiO}_{2}\right)$ nanoparticles

\section{Sample Preparation and Measurements}

At first the PSF dye solution is prepared without any nanoparticle. In one of our earlier works [21], we have mentioned the PVA solution making technique. Now $2 \mathrm{mg}$ of PSF is added in the solution and stirred for 10 minutes. One part of this solution is kept aside in a pre cleaned test tube. Then in the other portion of PSF dye solution, $2 \mathrm{mg} \mathrm{TiO}_{2}$ nanoparticles is added and well stirred. A PSF: $\mathrm{TiO}_{2}=1: 1$ solution is kept separated. In this solution $2 \mathrm{mg}$ of $\mathrm{TiO}_{2}$ is added for preparing 1:2 solution. Similarly, the $\mathrm{TiO}_{2}$ concentrations is increased to prepare 1: 3 and 1: 4 solutions of PSF : $\mathrm{TiO}_{2}$. After preparing the solutions, PSF solution without any nanoparticle is spin coated at 1500 rpm speed and dried at $3500 \mathrm{rpm}$ speed on a pre cleaned Indium Tin Oxide coated glass substrate. Similarly, the solution is deposited on the Aluminum (Al) coated mylar sheet and then ITO coated glass and Al-M are sandwiched together to form the cell. This cell and also other cells made of different solutions are vacuum dried for 12 hours. 
Concentrations of PSF: $\mathrm{TiO}_{2}$ in the other four cells are 1:1, 1:2, 1:3 and 1:4. Fig. 2 expresses schematic of Phenosafranin (PSF) dye based organic device. The thickness of each layer of the sandwiched structured device which are comprised of ITO electrode, PSF dye- nanoparticles composite and Al-M electrode are $1.3 \mu \mathrm{m}, 4 \mu \mathrm{m}$ and $1.7 \mu \mathrm{m}$ respectively.

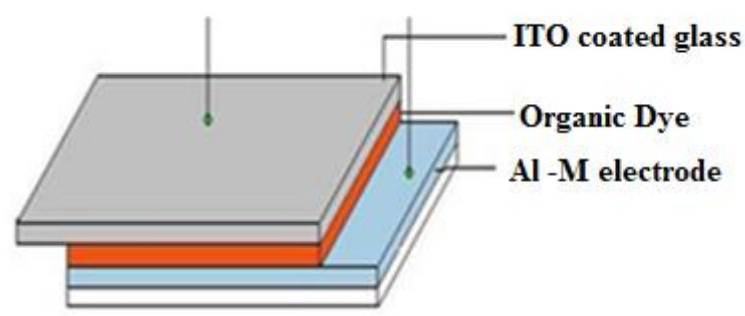

Fig. 2 Schematic diagram of the organic device

Figures 3 (a), 3 (b), 3 (c) and 3 (d) show the SEM images of four different concentrations of titanium dioxide nanoparticles in the four cells comprising of $\mathrm{PSF}: \mathrm{TiO}_{2}$ in the ratios of $1: 1,1: 2,1: 3$ and $1: 4$ respectively.

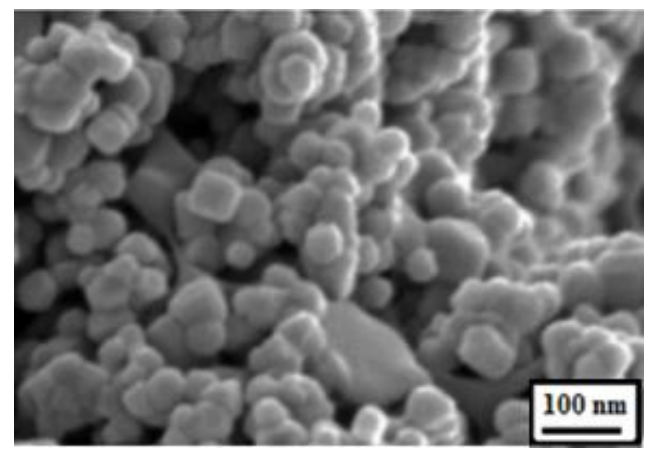

(a)

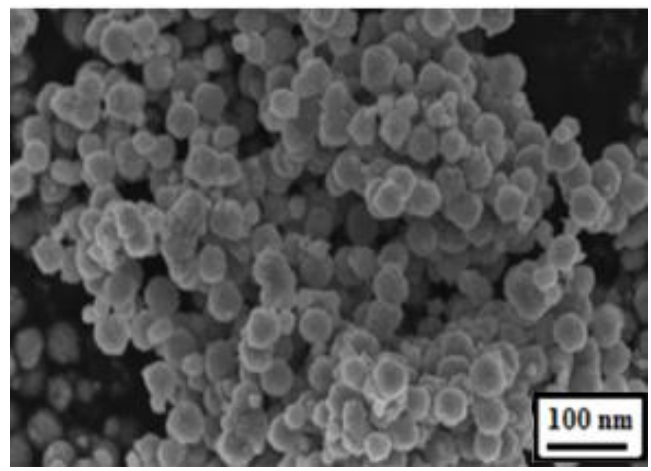

(c)

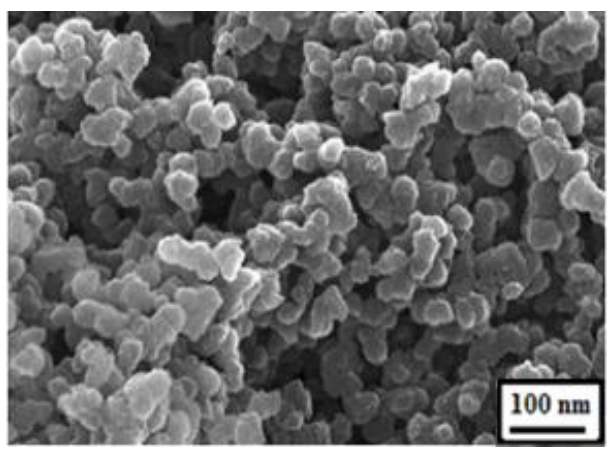

(b)

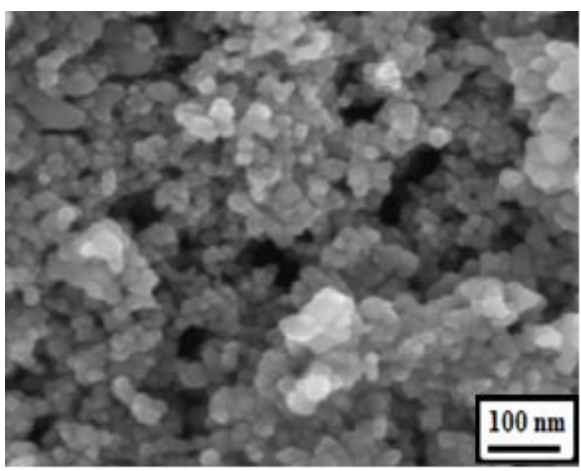

(d) 
Fig. $3 \mathrm{SEM}$ images of four different concentrations of $\mathrm{TiO}_{2}$ nanoparticles in four different organic devices comprising of PSF: $\mathrm{TiO}_{2}$ in the ratios of (a) 1:1, (b) 1:2, (c) 1:3 and (d) $1: 4$ respectively

In Fig. 3 (a) the SEM image reveals highly agglomeration of titanium dioxide nanoparticles. Agglomeration of nanoparticles affects the characteristics of nanoparticles and these agglomerates significantly decrease the number of nanoparticles in nanocomposites at a constant filler concentration [22]. The image in Fig. 3 (b) shows a slight decrease in agglomeration of titanium dioxide particles. Fig. 3 (c) shows SEM image which reveals clearly defined titanium dioxide nanoparticles. There are noticeable voids and pores on the surface. With increasing concentration of titanium dioxide nanoparticles, an alteration in the structure has been observed which is shown in Fig. 3 (d). It has been assumed that the observed big chunks are caused by higher supersaturation concentration of titanium dioxide nanoparticles since the atoms are readily available for random growth.

Keithley 2400 source measurement unit has been used for current - voltage measurement. In one of our earlier works, the detail of the current - voltage measurement technique is discussed [23]. The voltage range is kept in between 0 to $6 \mathrm{~V}$ in steps of $0.2 \mathrm{~V}$ with delay of $1000 \mathrm{~ms}$. The room temperature was kept at $25^{\circ} \mathrm{C}$.

\section{Results and Discussion}

Steady - state current - voltage (I - V) plot of the PSF organic device without any nanoparticle and with different $\mathrm{TiO}_{2}$ nanoparticles concentrations have been shown in Fig. 4. This figure shows that current improves with the increase $\mathrm{TiO}_{2}$ nanoparticles concentration. When the concentration ratio of $\mathrm{PSF}$ and $\mathrm{TiO}_{2}$ nanoparticles is $1: 4$, the current flow in the organic device is highest compared to other concentration ratios of PSF and $\mathrm{TiO}_{2}$ nanoparticles which are 1:1, 1:2 and 1:3 respectively. The current flow is lowest when there is no nanoparticle present in the PSF dye based device. We can infer from these I-V plots that, charge injection process gets improved in presence of nanoparticles which can be related to the filling of traps. These traps are also act like recombination centres. By filling the traps, charge flow gets improved due to the presence of $\mathrm{TiO}_{2}$ nanoparticles, which will also be resulting in potential barrier lowering at metal-organic contact. 


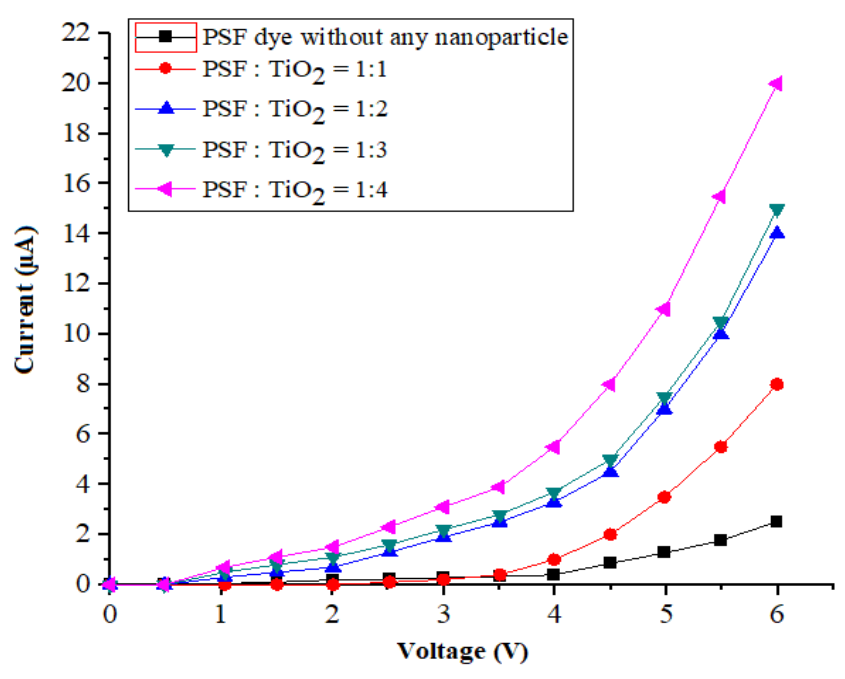

Fig. 4 Dark I-V plots of PSF dye without any nanoparticle and with different $\mathrm{TiO}_{2}$ nanoparticles concentrations

Potential barrier is estimated from semi-logarithmic I - V plot of organic device without any nanoparticle and with different $\mathrm{TiO}_{2}$ nanoparticles concentrations which has been shown in Fig. 5. This figure shows with introduction of $\mathrm{TiO}_{2}$ nanoparticles, the potential barrier is lowered. Potential barrier is smallest when the concentration ratio of PSF dye and $\mathrm{TiO}_{2}$ nanoparticles is $1: 4$ and it is highest for this device when no nanoparticle is present.

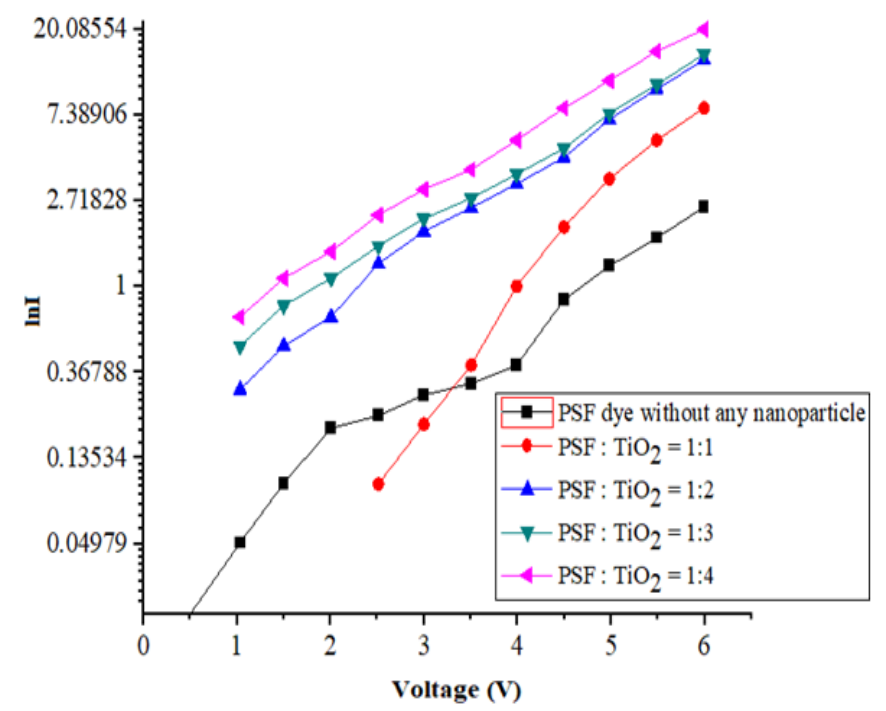

Fig. 5 Semi log I-V plots of PSF dye without any nanoparticle and with different $\mathrm{TiO}_{2}$ nanoparticles concentrations 
We have analyzed the current voltage characteristics of this PSF dye based device by using Richardson- Schottky (RS) model. Current is expressed as given by the following equation (1-2)

$$
\begin{gathered}
I=A A^{*} T^{2} \exp \left(-\beta \phi_{b}\right)\left(\exp \left(\frac{\mathrm{qV}}{n k T}\right)-1\right) \\
I_{0}=A A^{*} T^{2} \exp \left(-\beta \phi_{b}\right)
\end{gathered}
$$

Where, $\beta=(\mathrm{q} / \mathrm{kT})$ and $\mathrm{q}$ is the charge of electron, $\mathrm{V}$ is the voltage that is applied to the device, $\mathrm{A}$ is the device area, $\mathrm{k}$ is the Boltzmann's constant, $\mathrm{T}$ is absolute temperature, $\mathrm{A}^{*}$ is the effective Richardson constant, $\mathrm{n}$ is the ideality factor and $\phi_{\mathrm{b}}$ is the potential barrier and $\mathrm{I}_{0}$ is the saturation current [24-30]. The area of all the devices is of $1.5 \mathrm{~cm}^{2}$.

Determination of saturation current is done by finding Y-axis intercept of ln (I) vs V curves and $\phi_{\mathrm{b}}$ is obtained from $\mathrm{I}_{0}$ extrapolation in the semi log forward bias $\mathrm{I}-\mathrm{V}$ plot.

The potential barrier of prepared device can be estimated from equation (3) [31-32] which can be deduced from equation (2)

$$
\phi_{\mathrm{b}}=\frac{1}{\beta} \ln \left(\frac{\mathrm{AA}^{*} \mathrm{~T}^{2}}{\mathrm{I}_{0}}\right)
$$

We have also calculated potential barrier by Norde function. Norde function interrelates function $F(V)$ and the current I (V). The expression has been shown in the equation given below (4) and I (V) is the current, measured from I-V characteristics of the device where all symbols carry their usual meaning [33].

$$
\mathrm{F}(\mathrm{V})=\left(\frac{\mathrm{V}}{\gamma}\right)-\frac{1}{\beta} \ln \left(\frac{\mathrm{I}(\mathrm{V})}{\mathrm{AA}^{*} \mathrm{~T}^{2}}\right)
$$

where $\gamma$ is the first integer greater than $\mathrm{n}$.

In Fig. 6, the potential barrier is estimated without any nanoparticle and with different $\mathrm{TiO}_{2}$ nanoparticles concentrations. The expression is shown in the following equation (5) [34-35] where $F\left(V_{\min }\right)$ = minimum value of Norde function.

$$
\phi_{\mathrm{b}}=\mathrm{F}\left(\mathrm{V}_{\min }\right)+\frac{\mathrm{V}_{0}}{\gamma}-\frac{1}{\beta}
$$

Fig. 6 shows that with presence of $\mathrm{TiO}_{2}$ nanoparticles, potential barrier is lowered and the calculated values of this parameter remain consistent with the values obtained from device's I -V plot. The potential barrier estimated by Norde function also shows that $\phi_{\mathrm{b}}$ is lowest when the concentration ratio of PSF dye and $\mathrm{TiO}_{2}$ nanoparticles is $1: 4$ and it is highest when the device is fabricated without any nanoparticle. 


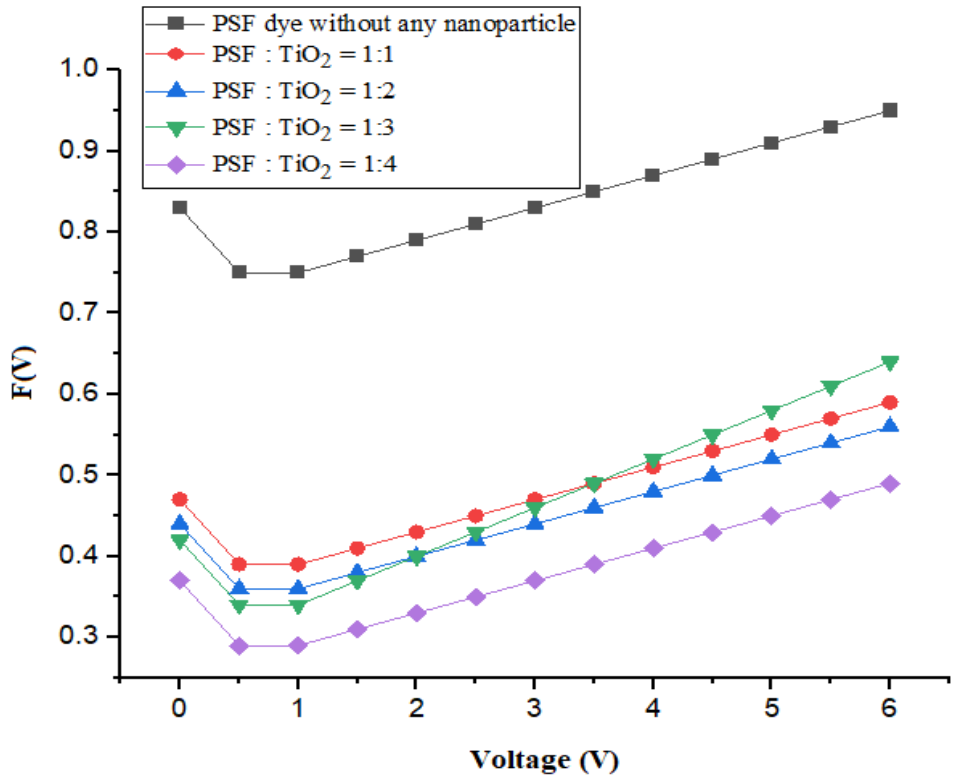

Fig. 6 Norde Function of PSF dye in absence of any nanoparticle and in presence of different concentrations of $\mathrm{TiO}_{2}$ nanoparticles

The calculated values of potential barrier from I-V plots and by Norde function is shown in Table I given below

Table I Calculation of Potential Barrier of PSF Organic device without any nanoparticle and with different $\mathrm{TiO}_{2}$ nanoparticles concentrations

\begin{tabular}{|l|l|l|}
\hline $\begin{array}{l}\text { Devices } \\
\text { (PSF:TiO2) }\end{array}$ & $\begin{array}{l}\text { Potential Barrier from I - V Plot } \\
(\mathrm{eV})\end{array}$ & $\begin{array}{l}\text { Potential Barrier from } \\
\text { Norde Function } \\
(\mathrm{eV})\end{array}$ \\
\hline Without any nanoparticle & $0.81 \pm 0.05$ & 0.83 \\
\hline $1: 1$ & $0.44 \pm 0.05$ & 0.47 \\
\hline $1: 2$ & $0.43 \pm 0.05$ & 0.44 \\
\hline $1: 3$ & $0.40 \pm 0.05$ & 0.42 \\
\hline $1: 4$ & $0.38 \pm 0.05$ & 0.37 \\
\hline
\end{tabular}

From the above table it can be seen from analyzing steady state I-V plots that both the methods are in unison in showing that potential barrier is reduced maximum in the PSF: $\mathrm{TiO}_{2}$ nanoparticles composition of 1:4.

\section{Conclusions}

In this work, we have estimated potential barrier at M/O contact of PSF organic device with different titanium dioxide $\left(\mathrm{TiO}_{2}\right)$ nanoparticles concentrations. The potential barrier has been estimated by using I-V plot of organic device. The values of potential 
barrier obtained from I-V plot analysis remain consistent with values estimated by using Norde method. It has been found out that the potential barrier is lowest for the highest concentration of $\mathrm{TiO}_{2}$ nanoparticles in the composite of PSF and $\mathrm{TiO}_{2}$ nanoparticles. When the concentration ratio of $\mathrm{PSF}$ and $\mathrm{TiO}_{2}$ nanoparticles is $1: 4$, it gives least potential barrier at the interface compared to other concentration ratios of PSF and $\mathrm{TiO}_{2}$ nanoparticles which are 1:1,1:2 and 1:3 respectively. The potential barrier is highest when the PSF organic device is formed without any nanoparticle. It can be inferred from these results that the presence of higher concentrations of $\mathrm{TiO}_{2}$ nanoparticles improve flow of charge by potential barrier lowering at M/O contact which can also be ascribed to filling of traps. The device conductivity will also be ameliorated due to improved charge flow at M/O contact.

\section{Acknowledgements}

Financial support under Grant No.3482/ (NET-JULY2016) from UGC, India are gratefully acknowledged by Sudipta Sen.

\section{Conflicts of Interest}

Both the authors declare that no conflict of interest is present regarding this present work.

\section{References}

[1] Eslamian M., Nano - Micro Lett., 9 (2017), 1.

[2] Kamedulski P., Kedziera a.K., Lukaszewicz J. P., B. Mater. Sci., 41 (2018), 1.

[3] Salem G.F., El - Shazly E.a.a., Farag a.a.M., Yahia I.S., Appl. Phys. a-Mater., 124 (2018), 1.

[4] Sen S., Manik N.B., Phys. Int., 10 (2019), 1.

[5] Sen S., Manik N.B., International Journal of Scientific Research and Review, 07 (2019), 10.

[6] Sen S., Manik N.B., Int. J. Adv. Sci. Eng., 6 (2020), 23.

[7] Sen S., Manik N.B., B. Mater. Sci., 43 (2020), 1.

[8] Tang H., Prasad K., Sanjinès R., Schmid P. E., Lévy F., J. Appl. Phys., 75 (1994), 2042.

[9] Mo S.D., Ching W. Y., Phys. Rev. B, 51(1995), 13023.

[10] Sen S., Manik N.B., Results in Materials, 8 (2020), 100145.

[11] Rozycka a., Iwan a., Filapek M., Gorska N., Bogdanowicz K. a., Dąbczyński P., Rysz J., Pociecha D., Hreniak a., Marzec M., Liq. Cryst., 45 (2017), 831.

[12] Zhang L.W., Fu H. B., Zhu Y. F., Adv. Funct. Mater., 18 (2008), 2180. 
[13] Rozycka a., Iwan a., Bogdanowicz K. a., Filapek M., Gorska N., Pociecha D., Malinowski M., Fryń P., Hreniak a., Rysz J., Dąbczyński P., Marzec M., Beilstein J. Nanotechnol., 9 (2018), 721.

[14] Rozycka a., Iwan a., Bogdanowicz K. a., Filapek M., Gorska N., Hreniak a., Marzec M., Dalton Trans., 47 (2018), 7682.

[15] Yang P., Zhong D. K., Yuan M., Rice a. H., Gamelin D. R., Luscombe C. K., Phys. Chem. Chem. Phys., 15 (2013), 4566.

[16] Lee K., Kim J. Y., Park S. H., Kim S. H., Cho S., Heeger a. J., Adv. Mater., 19 (2007), 2445.

[17] Arkhipova V.I., Seggern H.V., Emelianova E.V., Appl. Phys. Lett., 83 (2003), 5074.

[18] Sze S.M., Ng K.K., Physics of Semiconductor Devices, Wiley \& Sóns, New Jersey, 2007.

[19] Saha I., Hossain M., Kumar G.S., J. Phys. Chem. B, 114 (2010), 15278.

[20] Jia J., Yamamoto H., Okajima T., Shigesato Y., Nanoscale Research Lett., 11 (2016), 1.

[21] Sen S., Manik N.B., J. Electron Mater., 49 (2020), 4647.

[22] Ashraf M. a., Peng W., Zare Y., Rhee K. Y., Nanoscale Research Lett., 13 (2018), 1.

[23] Saha S., Manik N.B., Indian J. Physics, 89 (2015), 907.

[24] Yakuphanoglu F., Synthetic Met., 160 (2010), 1551.

[25] Jahangir I., Uddin M.a., Singh a.k., Koley G., Chandrashekhar M.V.S., Appl. Phys. Lett., 111 (2017), 1.

[26] Yildirim M., J. Polytech., 20 (2017), 165.

[27] Tung R.T., Appl. Phys. Rev., 1 (2014), 1.

[28] Yahia I.S., Zahran H.Y., Alamri F.H., Manthrammel M.a., Alfaify S., Ali a. M., Physica $B, 543$ (2018), 46.

[29] Güzeldir B., Sağlam M., Ates a., Türüt a., J. Alloys Compd., 627 (2015), 200.

[30] Yakuphnoglu F., Shah M., Farooq a.W., Acta Phys. Pol. a, 120 (2011), 558.

[31] Al-Ta'ii H.M.J., Amin Y.M., Periasamy V., Sensors, 15 (2015), 4810.

[32] Norde H., J. Appl. Phys., 50 (1979), 5052.

[33] Türüt a., Turk. J. Phys., 36 (2012), 235.

[34] Kocyigit a., Yilmaz M., Aydoğan S., Incekara Ü., J. Alloys Compd., 790 (2019), 388.

[35] Sağlam M., Güzeldir B., Mater. Res. Bull., 81 (2016), 55. 